\title{
Percepções de estudantes quanto os processos de mudança proposto pelo ensino médio politécnico no RS
}

\section{RESUMO}

Vanessa Vian seduc.profevanessa.vian@gmail.com 0000-0002-3267-4152 TaquariUnivates, Lajeado, RS, Brasil.

Lauren Heineck de Souza lauren heineck@hotmail.com 0000-0002-6839-5630 Pontifícia Universidade Católica do Rio Grande do Sul,Brasil.

Miriam Inês March mimarchi@univates.br 0000-0003-2546-7072

Docente do CETEC, do PPGCE e do PPG Ensino da Univates

Universidade do Vale do Taquari-

Univates, Lajeado, RS, Brasil.

\section{José Claudio Del Pino}

jose.pino@univates.br

Docente do PPG Ensino da Univate

Universidade do Vale do Taquari-

Univates, Lajeado, RS, Brasil.

Eniz Conceição Oliveira eniz@univates.br

(5)-2243

Docente do CETEC, do PPGCE e do PPG Ensino da Univates

Universidade do Vale do Taquari-

Univates, Lajeado, RS, Brasil.
O texto analisa documentos relacionados à proposta de reestruturação do ensino médio no RS (2011-2014), denominado ensino médio politécnico. A partir destes e da identificação dos princípios orientadores da proposta, um questionário composto por 22 afirmativas de estilo Likert foi aplicado a 153 alunos concluintes do ensino médio no ano de 2014, em duas escolas públicas no Vale do Taquari, RS. O Objetivo desta pesquisa foi analisar as percepções dos estudantes entrevistados quanto às mudanças sentidas por eles nas escolas onde estudam. Pelos resultados, podemos observar que os alunos não participaram na construção desta proposta, indicando pouca percepção de mudanças no meio escolar a partir da mesmas. Os alunos também evidenciam que, embora sentissem os professores pouco preparados para trabalhar na perspectiva da pesquisa, os mesmos demonstram envolvimento dentro das disciplinas que desenvolvem trabalhos com o uso da mesma, considerando que esta metodologia contribui para torná-los mais críticos

PALAVRAS-CHAVE: Ensino Médio Politécnico. Mudanças educacionais. Alunos. 


\section{INTRODUÇÃO}

A sociedade atual tem como marca a rapidez da informação que perpassa a simples ideia da transmissão comunicativa. Mais que isto, com o auge das inovações apresentadas pelo processo da globalização, as mudanças que se esperam são mais que de cunho estrutural: passam a ser paradigmáticas.

Desta maneira, os processos culturais, sociais, econômicos, políticos e tantos outros mais, ao apropriarem-se da rapidez e da mobilidade oferecida pelos recursos cibernéticos e globalizantes, ganham muito no quesito tempo. Ao invés de relações locais, tornam-se em rede e universais ultrapassando as barreiras físicas.

Em meio a este processo de rapidez e fluidez, a escola como instituição social parece resistir e não acompanhar as mudanças necessárias para que se estabeleça como elo entre o indivíduo em suas singularidades e o mundo em suas complexidades.

Em tempos atuais, denominados como era da informação e do conhecimento (ALARCÃO, 2008), a escola não se apresenta mais como único espaço para se buscar apenas informações, assim como, o professor não se caracteriza mais como sujeito transmissor do saber, sendo necessário ressignificar respectivamente seus papéis.

Libâneo (2013), indica estar longe o final dos tempos para a existência do professor ou da escola. Contudo, corrobora com o pensamento de que em tempos marcados pela informatização torna-se urgente remodelar o sentido de ambos, especialmente pelas exigências impostas pela sociedade comunicacional da atualidade, que procura por sujeitos capazes de produzir pensamento científico, desenvolver autonomia no pensar, apresentar competência reflexiva e interação crítica com as mídias, entre outros.

Azevedo e Reis (2014), ao analisarem a situação de estagnação que passa a educação pública geral no país, especialmente no ensino médio no Rio Grande do Sul, indicam o distanciamento entre o modelo que se estabelece na escola da atualidade e os avanços que se movimentam em torno da mesma, apresentando uma desconexão significativa entre ambos. Essa escola, pautada na pedagogia da repetição e na lógica curricular fragmentada, não colabora para que os indivíduos ingressantes em seu interior possam sair do meio escolar como sujeitos capazes de intervir no mundo do trabalho (Idem).

Por mundo do trabalho Azevedo e Reis (2014) definem a complexa realidade social da produção da vida, que engloba desde a produção de bens e mercadorias de caráter material e simbólico. Na denominação, os autores procuram situar a importância de promover um espaço escolar cuja realidade de vida e mundo, de cultura e economia, de política e situação social, possam ser debatidas. E nisto é que se insere na sociedade contemporânea, as novas formas de produção baseadas na pesquisa, na tecnologia e na ciência.

A metamorfose que se apresenta no mundo em seus setores, indica uma relação não linear, não estática, não precisa. Contudo, a escola ainda indica conter muitas das características citadas e a construção de uma marca escolar capaz de transformar a informação em conhecimento, parece ser o grande desafio nos tempos marcados pela contemporaneidade. 
Por meio deste texto, procuramos analisar as percepções de estudantes concluintes do Ensino Médio de duas escolas públicas no Vale do Taquari, Rio Grande do Sul, quanto às mudanças ocorridas nesta modalidade de ensino a partir da implantação do Ensino Médio Politécnico .

A proposta norteadora do Ensino Médio Politécnico apresenta críticas ao modelo tradicional de ensino e de escola, indicando um currículo estruturado de maneira diferente daquele que se estabelece por longa data de maneira praticamente homogênea em todo território nacional. Os principais fins que justificam a mudança estão focados nos altos índices de reprovação, abandono escolar, desconexão entre teoria e prática, a crítica feita ao descompasso sentido entre a realidade social e a realidade escolar como um todo, entre outros fatores.

Além disso, a proposta apresenta princípios orientadores, entre eles: relação parte-totalidade, reconhecimento de saberes, teoria e prática, interdisciplinaridade, avaliação emancipatória e pesquisa como princípio educativo (RIO GRANDE DO SUL, PROPOSTA, 2011-2014). Esses princípios, de maneira geral compõe o cenário atual das relações cotidianas das crianças e jovens, uma vez que por meio da comunicação e informatização em rede assim se estabelecem. Contudo, parecem se tornar uma barreira a ser vencida quando pensado no espaço escolar, que ainda sustenta as características tradicionais antes já citadas. É sobre o entendimento dos estudantes das escolas investigadas quanto suas percepções no que diz respeito às mudanças implantadas nas escolas investigadas a partir da implantação do ensino médio politécnico, que iremos tratar neste estudo.

\section{Metodologia}

Para a realização desta pesquisa utilizou-se o método quantitativo. Raupp e Bauren (2003) indicam que a escolha deste método se distingue da metodologia qualitativa pelo fato de não aprofundar o estudo em relação ao comportamento geral dos fatos analisados, baseando-se no emprego de dados e análise estatísticas. Gatti (2004) frisa que muitos questionamentos na área educativa não seriam feitos sem o apoio de levantamento de dados oriundos da quantificação.

Richardson (1999) indica que neste tipo de abordagem a quantificação é aplicada desde a coleta até o tratamento dos dados, podendo variar desde os mais simples, com uso de percentual, média e desvio padrão, até análises mais complexas.

Para analisar as percepções e o entendimento dos estudantes quanto ao processo de implantação do Ensino Médio Politécnico, foi elaborado e aplicado um questionário fechado, composto por 22 afirmativas de estilo Likert. No total, 153 estudantes de terceiro ano de Ensino Médio, oriundos de duas escolas públicas do Vale do Taquari - RS, que tem implementado o Ensino Médio Politécnico, responderam o questionário. A escolha da amostra se deve ao fato de que estes alunos, do terceiro ano do ensino médio, percorreram toda sua caminhada nas séries finais da educação básica na modalidade da politecnia, proposta pelo governo do estado do Rio Grande do Sul (2011-2014).

As respostas dos questionários foram analisadas a partir da utilização do software estatístico SPSS (Statistical Package for the Social Sciences), que gerou os percentuais que foram utilizados neste estudo. Para análise e discussão dos dados 
obtidos, as afirmativas serão representadas pela inicial $A$, seguida do número da afirmativa que corresponde, sendo assim expressas $A 1, A 2, A 3$, consecutivamente.

Para a constituição deste texto, serão analisadas as afirmativas $A 1, A 2, A 6, A 8$, $A 9, A 11, A 14, A 15, A 18$ e $A 22$, pois estas, em seu texto relacionam à temática da implantação do Ensino Médio Politécnico, os projetos de pesquisa e ao Seminário Integrado no ponto de vista dos alunos entrevistados.

\section{Modelos, políticas públicas, entendimentos e realizações no campo da educação pública}

Durkheim (1995) ao tratar da evolução pedagógica do ensino secundário na França, já indicava que as mudanças que estariam por vir na área educativa só tomariam forma, caso construídas de maneira coletiva. Contudo, para seu sucesso, ressaltava que os participantes deste projeto estivessem antes de tudo envolvidos, motivados e em condições de avaliar a proposta a qual estariam vivenciando. Desta maneira, o autor entendia que um programa educativo só teria validade pela maneira com o qual fosse aplicado e se feito na direção errada, com resignação passiva, poderia permanecer apenas no papel.

Valente (1999) afirma que as mudanças na área educativa no Brasil são lentas e quase imperceptíveis. Para tanto, não se pode afirmar que nenhuma iniciativa tenha sido proposta. Nos últimos tempos, especialmente o que diz respeito aos anos finais da educação básica, observa-se a inserção de leis e decretos favoráveis à reflexão para mudanças.

Neubauer et all (2011) indicam que a forte presença do ensino médio na agenda pública especialmente no início do século 21 diz respeito às mudanças culturais, sociais e tecnológicas da contemporaneidade. No mesmo sentido, as novas relações que se criam com o mundo do trabalho indicam a necessidade de preparar o público adulto para novas formas de pensamento, produção, relação.

É dessa forma que Libâneo (2013) aponta para as emergentes formas de estruturar o cenário educativo brasileiro, especialmente indicando que as rápidas mudanças que ocorrem em torno da escola refletem diretamente nela. Essas mudanças, oriundas do reflexo econômico, cultural, político, étnico, enfim, do mundo contemporâneo em si, indica significativo avanço no campo da comunicação e da informática, apresentando transformações tecnológicas e científicas, o que exige cada vez mais ênfase intelectual nas ações para estes campos. Nesse sentido, a necessidade da elaboração de políticas públicas na área educativa surgem com o propósito de diminuir as desigualdades e atender as singularidades das diferentes demandas do meio escolar pregando igualdade no que diz respeito ao acesso e à qualidade nos processos educativos.

As políticas públicas, conforme Abreu (1993, apud ESQUINSANI et all, 2006), podem emergir do interesse de governantes ou governados e estão associados aos agentes políticos, que devem implantá-las por meio de órgão institucionais aos quais pertencem. No que diz respeito aos avanços percebidos na legislação que trata do ensino Médio, observa-se que sua progressiva expansão como parte da educação básica ocorreu a partir da LDBN (9394/96). Neubauer et all (2011) indicam que, a partir da introdução desta lei, singularidades como heterogeneidade de idades, culturas, pensamentos, necessidade de formação docente diferenciada, métodos e estratégias de ensino diversas, também 
passaram a ser pontos observados nas séries finais da educação básica. Assim, outras leis, pareceres e decretos voltados ao ensino médio já focavam uma realidade a ser pensada de maneira diferenciada:

Visando a promoção de uma "escola jovem" e inclusiva, as Diretrizes Curriculares Nacionais (DCN) para o ensino médio - elaborados no Parecer CEB/CNE no15/98 e instituídas com força de lei pelo Conselho Nacional de Educação (CNE) por meio da Resolução no3/98 - fazem a crítica da transmissão de conteúdos enciclopédicos e dos métodos tradicionais de ensino, buscando colocar o aluno no centro do processo de aprendizagem. Para tanto, propõem como princípios norteadores do currículo o desenvolvimento de competências básicas, a interdisciplinaridade e a contextualização dos conteúdos, que tem em comum o protagonismo dos alunos e da comunidade (ibidem, p.13).

O indicativo de mudanças de cunho estrutural que aparece na década de 90, cujo foco era a indagação quanto o perfil de jovem que compunha a clientela/ público do ensino médio e a preocupação nas formas de como atendê-los, parecem assemelharem-se às preocupações expostas pela política pública instituída no Rio Grande do Sul, denominada Ensino Médio Politécnico.

O Ensino Médio Politécnico é uma proposta oriunda de um plano de governo, que passou a vigorar no cenário da educação pública gaúcha a partir do ano de 2012. Sendo assim, durante o mandato de governo gaúcho compreendido entre 2011-2014, é que se ampliaram as bases para a efetiva implantação nas escolas de educação básica em nível de ensino médio.

A proposta, se embasa na crítica ao modelo tradicional escolar vigente e passa a apresentar uma estruturação apoiada na pesquisa, na inter-relação com a tecnologia, no currículo pautado na ação interdisciplinar, na aproximação entre teoria e prática, entre outras indicações. Embasado em leis anteriores, entre elas a LDBN (9394/96) e a CNE de 31 de dezembro de 2012, o Ensino Médio Politécnico busca em sua proposta a relação com o trabalho intelectualizado, oriundo dos tempos atuais que dependem exclusivamente da tecnologia. Para isto, o documento base indica que:

Para desenvolver esse novo princípio educativo a escola é fundamental, uma vez que sua função precípua é ensinar a compreender e a transformar a realidade a partir do domínio da teoria e do método científico. Se o saber fazer poderia ser aprendido na prática, sem ou com reduzida escolaridade, o trabalho intelectualizado e a participação na vida social atravessada pelas novas tecnologias demandam formação escolar sólida, ampliada e de qualidade, principalmente para os que vivem do trabalho, para os quais a escola é o único espaço possível de relação intencional com o conhecimento sistematizado (RIO GRANDE DO SUL, PROPOSTA 2011-2014, p.13).

Se por um lado o texto indicativo da proposta parece se repetir com os textos de outras políticas e leis da década de 90, por outro, o ano 2000 já inicia com mais inclinação ao uso das tecnologias da informação do que uma década anterior e pelo que se percebe, a velocidade das mutações tende a ser cada vez mais rápida.

Da mesma forma, é notável destacar o espaço que se cria para a aceitação de novas propostas no ambiente escolar e a percepção de como os estudantes veem isso. Desta forma, Demo (2011, p.19-20) atenta para que, em meio às mudanças indicadas haja uma preocupação de envolvimento de todo o coletivo: 
Uma providência fundamental será cuidar que exista na escola ambiente positivo, para conseguir no aluno participação ativa, presença dinâmica, interação envolvente, comunicação fácil, motivação à flor da pele. A escola precisa representar, com máxima naturalidade um lugar coletivo de trabalho, mais do que disciplina, ordem de cima para baixo, desempenho obsessivo, avaliação fatal.

Desta forma, mantém-se válida a tentativa de promover modificações estruturais no sentido da escola e dos processos educativos, como aponta o documento base da proposta do Ensino Médio Politécnico. Contudo, o que nos faz investigar acerca desta temática é justamente o interesse em compreender como esta foi trabalhada no seio da escola, de que maneira os segmentos escolares foram mobilizados para tais mudanças e especialmente como os alunos estão percebendo tais indicativos, uma vez que muitas das propostas já apresentadas para o meio educacional permanecem restritas aos seus documentos de origem.

\section{Os dados e a análise}

De acordo com o documento base que indica a proposta de reestruturação do Ensino Médio no Rio Grande do Sul - Ensino Médio Politécnico (2011-2014), as mudanças desejadas para a educação básica em nível de ensino médio, são urgentes e pautadas nos diversos avanços apresentados no contexto social geral. Junto a isto, o documento aponta dados focados na realidade do ensino médio gaúcho, indicando altos níveis de repetência, abandono escolar, defasagem idadesérie, entre outros. Assim, a proposta apresenta os princípios orientadores que a sustentam e, de acordo com o documento, seriam implantadas após debate coletivo entre os diversos setores da sociedade e em várias etapas (RIO GRANDE DO SUL, PROPOSTA, 2011-2014).

No que se refere à participação dos diversos segmentos escolares no processo de estruturação do ensino médio Politécnico, um estudo de Azevedo e Reis (2014) indica que no total, 39 mil pessoas, entre professores, funcionários, especialistas da educação, pais e alunos, participaram das conferências que ocorreram no ano de 201 . Contudo, ao analisar os dados coletados entre os estudantes das escolas investigadas, observamos uma divergência no ponto de vista dos mesmos, especialmente quanto a maneira de como percebem que proposta do politécnico foi apresentada.

Conforme a afirmativa A2, que tem como texto "As mudanças a serem implantadas com a Proposta do Ensino Médio Politécnico passaram por consulta e participação coletiva dos alunos" tem $69 \%$ de discordância total ou parcial, enquanto apenas $16 \%$ concordam total ou parcialmente com o que é exposto. Ainda, $15 \%$ não discorda e nem concorda com o que está apresentado no texto. Essa afirmativa, ao indicar elevado nível de discordância apresenta contradição com aquilo que está exposto no documento da proposta: 
Como característica de governo, a prática democrática se instala neste processo de reestruturação a partir do debate deste documento - base e com participação de toda a comunidade escolar. Essa discussão, iniciada na escola, demarca a etapa desencadeadora do processo que culminará na Conferência Estadual do Ensino Médio, envolvendo a sociedade como um todo, pois o compromisso com a educação é de todos (RIO GRANDE DO SUL, PROPOSTA 2011-2014, p.3).

De acordo com Azevedo e Reis (2014), conferências em diversos níveis de localização foram realizadas para que ocorresse o debate da proposta implantada nas escolas de ensino médio no ano de 2012. Contudo, conforme esse mesmo estudo, os percentuais de participação em cada segmento variou consideravelmente até o momento da escolha final dos delegados que participaram da conferência estadual no mês de dezembro de 2011 em Porto Alegre. Para este debate, considerado o auge do processo que transcorreu durante o segundo semestre de 2011, um total de 450 delegados participou da conferência estadual. Isto indicaria os entendimentos transcorridos em todos os outros encontros anteriormente realizados, no momento das conferências municipais, regionais, inter-regionais. Assim, o número de delegados que compôs a conferência estadual esteve constituído por $75 \%$ de representantes do segmento professores, $5 \%$ do segmento funcionários, $15 \%$ do segmento alunos e $5 \%$ representado por pais (AZEVEDO e REIS, 2014). Desta maneira, o número real de estudantes que teriam participado do debate final no segundo semestre de 2011, contabiliza 67 estudantes (Ibidem).

Os dados expressos nas respostas dos estudantes podem ter relação com a pouca participação dos mesmos em cada etapa de elaboração dos nortes que seguiriam o ensino médio politécnico, uma vez que não indica a construção com a totalidade do universo de cada escola.

Além disso, os processos de debate, marcado pelos impasses e pelas dúvidas, muitas vezes podem ter rendido pouca clareza no novo modelo que iria ser constituído e posto em prática com o politécnico, o que pode ter causado dúvidas também no que diz respeito às próprias metodologias de trabalho exigidas para que ocorressem tais modificações. Desta forma, o segmento composto pelos professores pode também ter sido prejudicado, ao não compreender exatamente quais rumos seguir para desenvolver um trabalho que exigia a mudanças na prática, na concepção de avaliação, no entendimento do uso da pesquisa e do trabalho interdisciplinar.

Assim ao observar a afirmativa A1, que tem como texto "A Proposta do Ensino Médio Politécnico foi exposta de maneira clara e objetiva pelos professores da minha escola", teve aproximadamente $45 \%$ de discordância total ou parcial, enquanto que $32 \%$ concordam parcial ou totalmente com o que está exposto. 0 divisor de opiniões quanto a afirmativa feita pode ter relação direta com o número de professores e alunos participantes das conferências realizadas em diferentes níveis. Ou seja, depreende-se que muitos destes professores e destes estudantes não tenham participado nos encontros que trataram das novas bases que estruturariam o ensino médio em 2012.

Em estudo realizado, Balado (2014) aponta que o documento base da proposta de reestruturação do Ensino Médio Politécnico chegou às escolas pronto, o que gerou para os professores uma "ofensa", uma vez que: 
[...] Em momento algum houve qualquer ação que buscasse a elaboração conjunta e democrática que o documento pregava, já que ele chegou às escolas em formato conclusivo, visto que a sua apresentação não deixava qualquer margem para questionamentos ou rejeição e porque as equipes não se sentiam capacitadas para fazer uma mudança tão radical em tão pouco tempo (Ibidem, p.1).

O pensamento de Durkheim (1995), apresentado anteriormente também pode embasar esta ideia, sendo que, conforme o autor, sem o envolvimento intenso, construção coletiva e motivação por parte do grupo que faz parte dos modelos educacionais a serem propostos, sua realização torna-se um entrave. Dessa maneira, o texto do documento base, o qual indica que o processo de implantação ocorreria após longo debate entre comunidade escolar, parece não ter atingido quase metade dos estudantes entrevistados.

Além disso, o cenário de instabilidade que eventualmente se criou na escola, pode ter contribuído para uma desmotivação dos próprios professores diante da proposta, e desta forma, ter contribuído para os resultados indicados na afirmativa A1.

Ainda o que diz respeito às mudanças propostas pelo ensino médio politécnico, observa-se que o documento base propõe que o ensino seja contextualizado, de base interdisciplinar e de acordo com a realidade na qual o aluno está inserido. Para tanto, a concepção de conhecimento necessita buscar outro significado, uma vez que se trata de uma mudança ampla e conceitual.

Conforme o documento base, o conhecimento passa a ser entendido como algo provisório, que parte de um processo humano, histórico, de busca de compreensão e organização, que tem como origem a prática do homem em seus processos de transformação com a natureza (RIO GRANDE DO SUL, PROPOSTA 2011-2014). Em meio à concepção de conhecimento é que se explicita a necessidade de compreensão de currículo. Ribeiro (1993) aponta que o entendimento do conceito de currículo pode ser amplo, cuja compreensão pode variar desde a concepção formal e delimitadora de um instrumento, até um método de construção de ciência.

No que tange às mudanças curriculares propostas pelo ensino médio politécnico é que se analisa que a própria concepção curricular é apresentada de maneira diferenciada, sendo indicada como um conjunto de relações desafiadoras, capazes de resgatar o sentido da escola como espaço de desenvolvimento de aprendizagem, com sentido ao mundo real vivenciado pelos sujeitos deste meio. Assim, o documento base indica que os "conteúdos são organizados a partir da realidade vivida pelos alunos e alunas e da necessidade de compreensão desta realidade, do entendimento do mundo" (RIO GRANDE DO SUL, PROPOSTA 20112014, p.15)

Domingues, Toschi e Oliveira (2000), observam que os documentos relacionados às mudanças em torno do Ensino Médio na década de 90 , entre elas as propositadas pelos PCNs e pelos pareceres CEB/CNE no 154, de 25 de junho de 1998, e na Resolução CEB/CNE no 3, de 26 de junho de 1998, indicavam a necessidade de reorganização curricular. Segundo os autores, tornava-se clara a reflexão e ação em torno de modificações estruturais capazes de substituir a atual centralização sistêmica em termos de currículo e de gestão, para a autonomia das condições pedagógicas e curriculares da escola, priorizando a realidade que se 
insere cada instituição escolar. Para tanto, indicam tornar evidente a substituição de um modelo curricular estanque e disciplinar, por outro modelo, cujos princípios curriculares baseiam-se na interdisciplinaridade e na contextualização.

No mesmo sentido, o documento base da proposta de reestruturação do ensino médio (2011-2014) aponta para a importância da elaboração de um currículo voltado para a realidade sociocultural do aluno, uma vez que: "o currículo deverá considerar o significado sociocultural de cada prática, no conjunto das condições de existência em que ocorrem" (RIO GRANDE DO SUL, PROPOSTA 20112014, p.16).

Ao analisar a opinião dos estudantes entrevistados a respeito da percepção de modificações no currículo, a afirmativa A6: "Os conteúdos trabalhados são organizados a partir da realidade vivenciada em seu contexto" indicou $48 \%$ de discordância e $31 \%$ de concordância quanto ao que está sendo exposto. A divergência nas respostas pode representar que muito do que motivou os dados apresentados pelos alunos pode estar diretamente relacionado ao envolvimento dos mesmos nas demais mudanças ocorridas nessa modalidade de ensino.

Assim pode-se avaliar que a subjetividade muito pode ter contribuído para os dados divergentes nesta resposta. Em revisão feita por Mansano (2009), a autora divaga pela temática da subjetividade e analisando diversos teóricos pósmodernos como Foucault, Deleuze e Guatari, a autora sintetiza que esta, a subjetividade, é o resultado de julgamentos, crenças, hábitos e valores criados pelos indivíduos. Desta forma, a autora aponta que a subjetividade é oriunda de diversos elementos dispostos de maneira heterogênea no contexto social dos indivíduos, e por isso mesmo é que não se torna estanque.

Junto deste elemento, o resultado expresso no questionário também evoca a atenção no fator do relativismo das concepções postas para análise, uma vez que a compreensão dos dados expressos quanto as concepções de mudanças curriculares que passaram a existir, muito podem emergir da ideia e da percepção de currículo criada no decorrer da trajetória estudantil de cada aluno. Assim pode ser que enquanto para alguns estudantes a motivação inicial, o envolvimento em possíveis atividades diferenciadas refletiu no próprio entendimento da composição curricular, outros pelo envolvimento menor, puderam ter percebido com menos ênfase as mudanças ocorridas no próprio currículo a partir da implantação da proposta.

Outra ênfase apresentada pelo Ensino Médio Politécnico foi a implantação de um eixo articulador denominado Seminário Integrado. De acordo com o documento base, o espaço destinado ao Seminário Integrado compõe a parte diversificada do currículo, a qual promove o espaço para a pesquisa e o debate de temas transversais, os quais, em constante diálogo com a parte da formação geral, indica a articulação entre os dois blocos do currículo. Nas palavras do documento:

[...] constituem-se em espaços planejados, integrados por professores e alunos, a serem realizados desde o primeiro ano e em complexidade crescente. Organizam o planejamento, a execução e a avaliação de todo o projeto político-pedagógico, de forma coletiva, incentivando a cooperação, a solidariedade e o protagonismo do jovem adulto (RIO GRANDE DO SUL, PROPOSTA 2011-2014, p.24) prevê que o coletivo escolar assuma, coordene e acompanhe os projetos 
desenvolvidos nesse espaço de trabalho. Para tanto, a ampliação de carga horária torna-se uma necessidade emergente para que o tempo de desenvolvimento dos levantamentos das problemáticas locais possam ser evidenciadas e, consequentemente, postas em investigação por meio de projetos de pesquisa.

Um entendimento focado no espaço dedicado ao seminário Integrado, prevê uma adição, uma soma, um fechamento entre a formação geral e a parte diversificada, uma vez que este espaço pressupõe à articulação entre as áreas do conhecimento. Conforme o Regimento Padrão encaminhado para as escolas de nível médio no Rio Grande do Sul no ano de 2012:

A articulação dos dois blocos do currículo, formação geral e parte diversificada, se desenvolverá por meio de projetos construídos no Seminário Integrado, pela transversalidade de eixos, que oportunizam a apropriação da vida e as possibilidades no mundo do trabalho (RIO GRANDE DO SUL, 2012, p.7).

No entanto, o documento não prevê a perda no sentido disciplinar, mas a reestruturação, uma vez que o sentido educativo passa a priorizar metodologias que visem promover a construção de conhecimento de maneira diferenciada àquela que vinha ocorrendo e criticada pelo próprio documento. Contudo, ao analisar o entendimento dos estudantes quanto a inserção do eixo do seminário integrado, há uma apresentação de perda, prejuízo no currículo. Pelo texto da A9 "A introdução do Seminário Integrado trouxe prejuízos para as demais disciplinas", apresenta que $63 \%$ concordam com o que está sendo exposto, enquanto apenas $22 \%$ discorda total ou parcialmente do enunciado.

O resultado expresso nesta afirmativa pode ser justificado por uma possível incompreensão da própria equipe gestora e pedagógica ao organizar a matriz curricular que seria posta em ação nos anos da implantação do ensino politécnico. Desta forma, o entendimento claro do que representaria a parte diversificada e de formação geral, poderiam colaborar para as definições dos conceitos que se empregaram na organização curricular.

Conforme o documento base da proposta, o ensino politécnico visa articular uma parte de formação geral sólida, oriunda de uma integração de nível fundamental, a uma parte diversificada "vinculada a atividades da vida e do mundo do trabalho", o qual possa significar essas relações a favor da construção da cidadania, desenvolvimento econômico, ambiental, social, garantindo a qualidade de vida a todos (RIO GRANDE DO SUL, PROPOSTA, 2011-2014, p.23).

Desta forma, o mesmo documento evidencia que, a parte diversificada é composta pelo seminário integrado e pelas disciplinas de línguas estrangeiras, ensino religioso (conforme cada escola e legislação pertinentes) além de horas para as áreas das linguagens, matemática, ciências humanas e ciências da natureza, respectivamente com suas tecnologias. Assim, a sugestão indicada pelo documento base apresentava 6 horas semanais para parte diversificada no primeiro ano do ensino médio politécnico, 12 horas no segundo ano e 17 horas no terceiro. O documento também indica que esta organização não é rígida, adequada conforme a matriz curricular de cada escola.

Assim, observa-se que as horas divididas entre a parte de formação comum (disciplinas puras) e a parte da formação diversificada tem o propósito de se complementar, uma vez que, mesmo garantindo muitas horas na parte 
diversificada do terceiro ano, estas deveriam ter o propósito de continuidade no que se refere ao desenvolvimento de conceitos, aproximando a oportunidade de se trabalhar de maneira prática e interligada com as áreas do conhecimento.

Não se percebe, nessa perspectiva, que haveria diminuição da participação das demais disciplinas. O que entra em questionamento é: $O$ processo de articulação de conceitos foi claro para os professores, para os gestores e coordenadores pedagógicos? Os professores desenvolveram um trabalho articulado a fim de proporcionar ao aluno o entendimento desta integração? Como ocorre o planejamento destas atividades? Com isso, voltamos a ressaltar a questão da construção da proposta. Constatado anteriormente, a mesma indica ter sido posta de maneira muito definida no meio escolar, o que pode ter ocasionado a incompreensão de como seria trabalhar em um modelo que se propunha quebrar muitos dos padrões estabelecidos no meio escolar há anos, entre eles: fragmentação se saberes, unitarização disciplinar, turno escolar único, repetição e memorização.

Para tanto, o que tange a percepção dos alunos quanto o envolvimento dos professores de seminário integrado, a A11 "Os professores do Seminário Integrado mostram-se envolvidos com sua disciplina e com a pesquisa", indica $54 \%$ de concordância com a afirmativa, enquanto que $20 \%$ discordam total ou parcial e $26 \%$ não discordam e nem concordam com o enunciado.

O envolvimento dos professores para o desempenho de tarefas dentro do eixo articulador apresenta percepção positiva por parte dos estudantes. Este dado pode indicar que muitos destes professores aderiram as mudanças propostas como uma forma de promover modificações nos processos educativos vigentes. Estas, podem estar atreladas ao desejo de uma nova concepção na forma de pensar a função docente. Conforme indica Martins (2005, p.40):

\section{O professor tem de deixar de ser mero passador de informação em sala de aula para tornar-se incentivador do conhecimento, facilitador do processo de aprender de seus discípulos, estimulando-lhes a curiosidade pelo questionamento e ensinando-os a pensar e refletir sobre o que aprendem.}

Para tanto, os dados coletados na afirmativa A11 indica garantia de que os mesmos tenham sido preparados para tais mudanças. Corrobora com a ideia o resultado da A8, cujo texto apresenta: "Os professores que atuaram na disciplina de Seminário Integrado estavam preparados para atuar por meio da pesquisa", mostra 55\% de discordância no entendimento dos alunos, enquanto $24 \%$ concordam total ou parcialmente com a afirmativa.

Desta forma, analisa-se que, desde os processos de formação docente até o envolvimento dos mesmos para construção da proposta podem ter ficado comprometidos. Um estudo realizado por Freinberger e Berbel (2010), indica que os professores pouco se instrumentalizam da pesquisa como prática pedagógica e com isso, acabam repetindo uma educação por cópia.

\footnotetext{
Entendemos que essa educação pela pesquisa só será possível por meio de um novo pensar diante das concepções de ensino e aprendizagem, do papel do professor, conhecimento e pesquisa, a partir de reflexões acerca dessas questões durante o processo de formação inicial e continuada dos professores (Ibidem, p.211).
}

\section{E ainda continuam:}


Se o professor aprende apenas a reproduzir conhecimentos, como poderá, em sua atuação, exercer práticas pedagógicas investigativas que exigem o desenvolvimento do pensamento crítico e outras habilidades que, por sua vez, não foram exercitadas em seu processo de formação? Como poderá promover situações de ensino e aprendizagem que contemplem a (re)construção de conhecimentos e não somente a cópia e a reprodução dos mesmos a seus alunos, se não as experienciou (p.219).

No mesmo sentido, Galiazzi e Moares (2002) apontam que a formação docente é duramente criticada pela incapacidade de estabelecer relação entre a teoria e a prática. Os autores defendem a ideia de que a educação pela pesquisa "é um modo, tempo e espaço de formação que possibilita superar esta limitação, porque o formador e o licenciando, pelo educar pela pesquisa, podem assumir suas próprias teorias pedagógicas" (Ibidem, p.251).

A importância atribuída à utilização da pesquisa como prática utilizada na sala de aula é cada vez mais indicada por diversos autores, especialmente quando relacionada a uma forma de colaborar para a constituição de sujeitos mais autônomos. Freire (1996) aponta a pesquisa, como um dos caminhos para atingir a emancipação dos sujeitos. Demo (2004) aponta a pesquisa em sala de aula como condição de transformar e intervir no destino e na vida das pessoas e sociedades a fim de que estas possam criar sua própria história. Galiazzi e Moraes (2002) e Galiazzi (2011) indicam educar pela pesquisa, ou mesmo, a pesquisa como princípio educativo como momento para reflexão, ação, leitura, escrita, argumentação, caminho para o desenvolvimento de sujeitos autônomos.

Conforme o documento norteador da proposta do ensino médio politécnico, a prática da pesquisa é um dos princípios orientadores que a sustenta. Como expressa o documento, a pesquisa pedagogicamente estruturada favorece o desenvolvimento de sujeitos mais críticos, capazes e reflexivos (RIO GRANDE DO SUL, PROPOSTA, 2011-2014, p.20).

A incorporação da pesquisa na prática pedagógica é a garantia da construção de novos conhecimentos, a partir da articulação da análise de seus resultados com o acúmulo científico das áreas de conhecimento, para dar conta da necessidade ou realidade a ser transformada (RIO GRANDE DO SUL, PROPOSTA, 2011-2014, p.21).

Martins (2005, p.45) indica que, enquanto a disciplina tem o objetivo de transmitir saber, a pesquisa deve ser entendida como construção pedagógica que dispõe de uma conjunção global de disciplinas que fornecerão suporte para a busca de novos conhecimentos. "O projeto de pesquisa escolar é, pois, uma síntese multidisciplinar em que a visão e o enfoque de diversas matérias concorrem para ampliar e facilitar o conhecimento temático proposto nos seus objetivos".

Ao analisar a percepção dos estudantes entrevistados quanto a relevância da introdução da prática da pesquisa, conforme indica a A15 "Os estudantes têm apresentado envolvimento e produção positiva na pesquisa", observa-se que $51 \%$ dos entrevistados discordam com o enunciado, enquanto $22 \%$ concordam.

Este dado pode indicar que uma minoria dos estudantes estejam envolvidos com a prática da pesquisa que vem sendo desenvolvida na escola, por meio da disciplina de seminário integrado e demais ações promovidas pelas área do conhecimento. Dessa forma, Demo (2007, p.19-20) salienta que: 
Uma providência fundamental será cuidar que exista na escola ambiente positivo, para conseguir no aluno participação ativa, presença dinâmica, interação envolvente, comunicação fácil, motivação à flor da pele. A escola precisa representar, com máxima naturalidade um lugar coletivo de trabalho, mais do que disciplina, ordem de cima para baixo, desempenho obsessivo, avaliação fatal.

No sentido apresentado por Demo (2007), também Galiazzi (2001) destaca importância. Segundo a autora, é necessário estabelecer um processo lógicosistemático, analítico, argumentado, além do clima de diálogo crítico, construído e reconstruído constantemente por meio de leitura, escrita e argumentação. É frisado que nesse processo tanto professora quanto aluno estejam engajados para atuar na perspectiva da pesquisa.

Partindo da relação de importância e contribuição que a pesquisa oferece àqueles que dela se apropriam é que se estabelecem conexões entre o meio e as matérias, a teoria e a prática, a identificação e a resolução de problemas. Com isso os dados oriundos da A16 apontam para uma concordância de $50 \%$ no que se refere ao texto "As pesquisas têm abordado o lado teórico (leituras) e prático (experiências, observações)", enquanto $27 \%$ discordaram com o enunciado. Dessa maneira, a percepção dos estudantes quanto a relação estabelecida no processo transcorrido pela pesquisa, pode indicar que uma caminhada que, embora pequena, tenha traçado algumas relações no contexto geral que estão inseridos estes estudantes.

O meio social configura-se enquanto um espaço que pode favorecer a identificação e o estudo de problemáticas, uma vez que a pesquisa surge de um questionamento que parte do meio em que o sujeito está inserido e de suas vivências anteriores. Conforme Demo, (2008, p.52):

\footnotetext{
Podemos fazer um paralelo com a "solução de problemas". É comum na discussão sobre aprendizagem que esta se tornaria mais palatável se fosse direcionada à solução de problemas, uma terminologia diferente para o que se chama atualmente de aprendizagem situada. Em vez de aprendizagem abstrata, distanciada da vida, tentam-se modos de aproximar o que se aprende na vida concreta.
}

Nesse sentido, o documento base indica que haja o levantamento de informações do contexto social, partindo da realidade social do estudante, a fim de que este visualize possibilidades de agregar novos conhecimentos e tornar sua aprendizagem mais significativa e contextualizada (RIO GRANDE DOS SUL, PROPOSTA 2011-2014).

Esse movimento de integração e reconhecimento do meio, indicando um caráter investigativo, a busca por respostas ou entendimentos de fatos de como e por que ocorrem no meio em que vivem os estudantes, a busca por explicações científica, a comprovação de dados, enfim, são condições apresentadas pela utilização de pesquisa por parte dos alunos em aula, como indica Moraes (2012, p.99) criticados no sentido de melhoria de sua qualidade. 
Dessa forma, o ambiente que se desenvolve na escola por meio da introdução da pesquisa pode muito favorecer a identificação de um espaço constituído de maneira diferenciada, pela ruptura com o modelo vigente de ouvir e reproduzir, para a constituição focada no movimento de aproximação de situações reais a objetos reais (DEMO 2007).

Martins (2005, p.38) ainda indica que "os projetos não são métodos, nem aplicação de fórmulas com regras, mas têm elementos comuns com outros procedimentos, outras estratégias de ensino e devem estar em sintonia e conexão com os conteúdos do currículo escolar".

O envolvimento dos alunos neste movimento torna-se imprescindível para que haja autonomia e para que seja possível a aprendizagem através da pesquisa. Uma vez que esse envolvimento não ocorre, torna-se impraticável atingir os objetivos propostos pelo Ensino Médio Politécnico nesta perspectiva.

Ainda no que se refere às mudanças propostas para o ensino médio politécnico, outro ponto de destaque é que as modificações sugeridas venham colaborar com a formação de sujeitos mais críticos. Para isso, o documento busca respaldo em legislações já firmadas, entre elas a LDB 9394/96, como forma de embasar os rumos apresentados.

Contudo, o que se observa por meio da afirmativa A22 "A reestruturação do Ensino Médio Politécnico tem favorecido a formação de sujeitos mais críticos", pode-se perceber que $43 \%$ dos alunos não consideram que isto ocorre, pois discordam total ou parcialmente com o enunciado, enquanto $25 \%$ dos alunos que responderam ao instrumento de coleta que concordam total ou parcialmente. Além disso, 32\% não concorda nem discorda da afirmação.

Levando em consideração as próprias contribuições que o uso da pesquisa na sala de aula pode favorecer, entre eles a constituição da autonomia dos sujeitos Demo (2007), Galiazzi e Moraes (2002), Galiazzi (2011), e desta forma, sua relação direta para a definição de criticidade, é que se observa que incompreensões possam estar permeando o espaço escolar onde se focaliza nossos sujeitos de estudo. Desta forma, novamente a subjetividade no entendimento a respeito da criticidade pode ser um fator de destaque na divisão de opiniões. O que o aluno entende por sujeito crítico? Diferencia senso crítico de outro tipo de crítica? Poderia ele perceber que a crítica é realizada apenas para apontar erros no processo vivenciado? Percebe ele que a crítica embasada é a favor da construção de um espaço social, cultural e político diferenciado, o qual, por meio de suas próprias ações e indicações passará a construir?

As diversas evidencias podem justificar o resultado expresso acima, além do próprio fato de os alunos poderem estar sentido que do ensino "tradicional", demarcado aqui como aquele vivenciado por eles exclusivamente durante o ensino fundamental para o ensino médio, poucas mudanças podem ter ocorrido. Neste caso, um ensino cuja essência metodológica tenha priorizado a repetição e a memorização pouco pode contribuir para a constituição de sujeitos atuantes, perceptivos, reflexivos, enfim, críticos (DEMO, 2007). 


\section{Considerações finais}

Ao analisarmos o modelo escolar que se apresenta no contexto geral da educação brasileira, percebe-se um desnível notório quanto aos avanços observados no contexto geral da sociedade atual e no que se refere aos avanços sentidos na escola.

Esse fato, principalmente justificado quando relacionado à rapidez em que ocorrem os processos de comunicação e informação, acabam por se fazer presentes na escola quando pensada como um espaço que até pouco tempo atrás se buscava especialmente este tipo de contato: informação (mascarada como aprendizagem).

Os tempos atuais, ao indicarem a rapidez, clamam pela reestruturação de modelos educacionais que possam favorecer aos indivíduos a condição de construir conhecimento por meio da bagagem comunicacional que é disposta cotidiana e globalmente (LIBÂNEO, 2013).

Assim ao analisarmos as diversas leis e políticas públicas focadas no ensino médio brasileiro nas últimas décadas, focamos nosso estudo sobre as inovações apresentadas pelo Ensino Médio Politécnico no Rio Grande do Sul (2011-2014). Este, ao constituir-se como política pública, apresenta diversas frentes de atuação, indicando a aproximação entre teoria e prática, pesquisa como prática pedagógica, interdisciplinaridade, avaliação emancipatória, ampliação de carga horária, entre outros.

Por meio de um questionário aplicado a 153 estudantes de duas escolas públicas no Vale do Taquari, analisamos seus entendimentos quanto as principais mudanças percebidas por eles.

Em revisão teórica apresentada por Vian e Del Pino (2014), os autores apresentam o que há de novo no ensino médio politécnico não é a politecnia em si, uma vez que esta já é apresentada décadas anteriores. O que é apontado pelos autores como inovação na proposta, é a indicação da utilização da pesquisa como política pública nas séries finais da educação básica e esta, se trabalhada desde os processos formativos dos professores, muito pode contribuir na constituição de um perfil de sujeitos - professores e alunos, críticos e atuantes no meio social.

Pelo que podemos identificar, os estudantes não sentem significativas mudanças ocorridas com a introdução do ensino médio politécnico. Primeiramente, os resultados apresentam que houve pouca participação do segmento dos estudantes para a construção da proposta, além de os mesmos não sentirem clareza por parte dos professores quanto o entendimento da mesma.

No decorre do trabalho, os alunos também não consideraram significativa a relação feita entre conteúdos trabalhados na nova organização curricular e a realidade vivenciada pelos mesmos, considerando inclusive que ocorreram perdas, ou prejuízo no que diz respeito às disciplinas, quando da inserção do eixo articulador denominado seminário integrado.

Os alunos entrevistados também indicam que no momento da implantação da proposta, não sentiam os professores preparados para atuarem por meio da pesquisa, porém, os alunos indicam que percebem o interesse e o envolvimento significativo o envolvimento dos próprios alunos com a utilização da pesquisa, fato 
que se abre para novas e amplas discussões, uma vez que, desde as compreensões do conceito de pesquisa até sua prática, muitas oscilações podem ser encontradas.

Os alunos, em sua maioria, também observam que as pesquisas realizadas abordam o lado teórico e prático, indicando a percepção de que os mesmos observam e compreendem a existência desta aproximação e complementação.

Contudo, a maioria dos entrevistados, $43 \%$, não considera que a partir das mudanças ocorridas no ensino médio politécnico tenha sido favorecida a constituição de sujeitos mais críticos, um dos grandes objetivos embasados no documento base da proposta.

Desta forma, evidenciamos que a necessidade de modificações na estrutura dos modelos escolares, principalmente de ensino tornam-se evidentes, especialmente em meio à sociedade da informação. Para tanto, analisando as propostas existentes de modificação, no caso do ensino médio politécnico, observa-se que o fato de não ter sido construída junto da comunidade escolar de forma a favorecer o surgimento de peculiaridades e anseios oriundos da própria comunidade, pode ter desfavorecido todo o desenvolvimento da mesma no decorrer dos três anos.

Da mesma forma, a insegurança, as dúvidas e o próprio entendimento de conceitos abordados no documento base podem ter gerado indiferença na forma de assumir, estudar e colocar em prática a proposta do ensino médio, indicando uma certa resistência às mudanças curriculares e metodológicas propostas. 


\title{
Students' perceptions regarding the process of changes proposed by the polytechnic education in RS
}

\begin{abstract}
The text analyzes some documents relative to the proposal for restructuring intermediate education in RS (2011-2014), named polytechnic intermediate education. From those documents and the identification of the proposal guiding principles, a Likert style questionnaire containing 22 statements was applied to 153 graduating students from intermediate education in 2014 at two public schools in the Vale do Taquari, RS. The research aimed to analyze the perceptions of interviewed students regarding the changes they have felt at the schools where they study. From the results, it can be observed that the students did not take part in the construction of the proposal, showing little perception of changes in the school environment following the proposal. Students also made evident that, although they felt the teachers were underprepared to work under the research perspective, those same teachers demonstrated involvement within the subjects that develop works through research, whereas this methodology contributed to make them more critical.
\end{abstract}

KEYWORDS: Polytechnic Intermediate Education .Educational changes. Students. 


\section{REFERÊNCIAS}

ALARCÃO, Isabel. Professores reflexivos em uma escola reflexiva. 6a Ed. São Paulo, Cortez, 2008.

AZEVEDO, José C; REIS, Jonas T. Democratização do Ensino Médio: a reestruturação curricular no RS. (In) AZEVEDO, José C; REIS, Jonas ( Orgs.) 0 Ensino Médio e os desafios da experiência. São Paulo, Fundação Santillana. Moderna, 2014, p. 21-44.

BALADO, Maria do Carmo L. Organização curricular do ensino médio politécnico no RS. X ANPED SUL, Florianópolis, outubro, 2014.

BRASIL. Ministério da Educação. Lei no 9.394/1996. Disponível em:

<http://www.planalto.gov.br/ccivil 03/leis/19394.htm> Acesso em 25/01/2014.

DEMO, Pedro. Professor do futuro e reconstrução do conhecimento .Petrópolis, Rj. Vozes, 2004.

DEMO, Pedro. Metodologia para quem quer aprender. São Paulo: Atlas, 2008.

DEMO, Pedro. Educar pela pesquisa. 8 $^{a}$ ed. Campinas. São Paulo: Autores Associados, 2007.

DEMO, Pedro. Educar pela pesquisa. 9ạ ed.revista. -Campinas, SP: Autores Associados, 2011.

DOMINGUES, José L., TOSCHI, Nirza S., OLIVEIRA, João F. A reforma do Ensino Médio: A nova formulação curricular e a realidade da escola pública. Educação e Sociedade, ano XXI, no 70, Abril/2000.

DURKHEIM, Emile. A evolução pedagógica. Porto Alegre: Artes Médicas, 1995.

ESQUINSANI, Rosimar Serena Siqueira. Et. al. Gestão e politicas educacionais: do que estamos falando, mesmo? Aportes teóricos-conceituais para delimitação de termos. ( In) CAMARGO, leda de. (Org.) Gestão e politicas da educação. Santa Cruz do Sul: EDUNISC, 2006. 
FREINBERGER, Regiane M.; BERBEL, Neusi A. A importância da pesquisa como princípio educativo na atuação pedagógica de professores de educação infantil e ensino fundamental. Cadernos de Educação | FaE/PPGE/UFPel | Pelotas [37]: 207 - 245, setembro/dezembro 2010

FREIRE, Paulo. Pedagogia da autonomia: Saberes necessários à Prática educativa. 18ed. São Paulo: Paz e Terra, 1996.

GALIAZZI, Maria do Carmo; MORAES, Roque. Educação pela pesquisa como modo, tempo e espaço de qualificação da formação de professores de ciências. Ciência e Educação, v.8, no2, p.237-252, 2002.

GALIAZZI, Maria do Carmo. Educar pela pesquisa: Ambiente de formação de professores de ciências. Ijuí: Ed. Unijuí, 2011.

GALIAZZI, Maria do Carmo; et al. Objetivos das atividades experimentais no Ensino Médio: a pesquisa coletiva como modo de formação de professores de ciências. Ciência \& Educação, v.7, n.2, p.249-263, 2001.

GATTI, Bernardete. Estudos quantitativos em educação. Educação e Pesquisa, São Paulo, v.30, n.1, p. 11-30, jan./abr. 2004.

LIBÂNEO, José Carlos. Adeus professor, adeus professora? Novas exigências educacionais e formação docente. São Paulo, Cortez, 2013.

MANSANO, Sônia R.V. Sujeito, subjetividade e modos de subjetivação do sujeito na contemporaneidade. Revista de psicologia da UNESP, 8 (2), 2009, p.110

MARTINS, Jorge Santos. Projetos de pesquisa: estratégias de ensino e aprendizagem em sala de aula. Campinas, São Paulo. Armazém do Ipê, 2005.

MORAES, Roque. Educar pela pesquisa: exercício de aprender a aprender ( In) MORAES, Roque ; LIMA, Valderez Marina do Rosário ( Orgs.) Pesquisa em sala de aula: tendências para a educação em novos tempos. 3aed. Porto Alegre: Edipucrs, 2012, p.93 -104.

NEUBAUER, Rose et all (coord.). Ensino Médio no Brasil: uma análise de melhores práticas e políticas públicas. Revista brasileira de Est.pedag. Brasília,vol.92, no 230, p.11-33, jan./abril, 2011 
RAUPP, Fabiano Maury; BEUREN, Ilse Maria. Metodologia da pesquisa aplicável às ciências sociais. In: BEUREN, Ilse Maria (Org.). Como elaborar trabalhos

monográficos em contabilidade: teoria e prática. São Paulo: Atlas, 2003. p. 76-97.

RIBEIRO, Victória Maria B. A construção do conhecimento, o currículo e a escola básica. Em Aberto, Brasília, ano 2012, no 58, abr/jun.1993.

RICHARDSON, Roberto J. Pesquisa Social: Métodos e técnicas. 3 ed. São Paulo, Atlas, 1999.

RIO GRANDE DO SUL. Secretaria da Educação. Proposta pedagógica para Ensino Médio Politécnico e Educação Integrada ao Ensino Médio 2011-2014. Disponível em:< http://educacao.rs.gov.br/dados/ensmedproposta.pdf> Acesso em 24 de julho de 2013.

RIO GRANDE DO SUL. Secretaria da Educação. Regimento referência das Escolas de Ensino Médio Politécnico da Rede Estadual. Parecer CEED no 310/2012.Disponível em: < http://www.educacao.rs.gov.br/dados/ens.> Acesso em 24 de julho de 2013 .

VALENTE, José Armando (Org.). O computador na sociedade do conhecimento. Ministério da Educação. Secretaria da educação à distância. 1999.

VIAN, Vanessa; DEL PINO, José Claudio. Ensino Médio Politécnico: práticas inovadoras desafiando a formação docente. Signos, ano 35, nำ1,63-75,2014.

\section{Como citar:}

VIAN, V.; SOUZA, L. H. DE; PINO, J. C. D.; MARCHI, M. I.; OLIVEIRA, E. C. Percepções de estudantes quanto os processos de mudança proposto pelo ensino médio politécnico no RS. Revista Brasileira de Ensino de Ciência e Tecnologia, v. 10, n. 2, 2017. Disponível em:

<https://revistas.utfpr.edu.br/rbect/article/view/2823>. Acesso em: xxx.

Correspondência:

Direito autoral: Este artigo está licenciado sob os termos da Licença Creative Commons-Atribuição 4.0 Internacional. 
